\title{
Smart Growth, Smart City
}

\author{
Zhe $\mathrm{Li}^{1, \mathrm{a}}$ \\ ${ }^{1}$ Department of Mathematics and Physics, North China Electric Power University, Baoding 071003, \\ China \\ alizheee@foxmail.com
}

\begin{abstract}
Smart growth, a strategy to build sustainable cities, has been proposed to prevent urban sprawl, for example, by using compact development. This paper develops Smart Growth Measure Model to measure the success of smart growth of a city, and uses two specific cases to demonstrate the model. Based on the three E's of sustainability, 14 indicators from the economic, social and environmental aspects are selected to build a multi-level Smart Growth Indicators system. We then use the Full Permutation Polygon Synthetic Indicator Method to compute the Comprehensive Indicator (CI) and use it as an indicator to measure the success of smart growth. At last, two cities, Hartford, US and Bloemfontein, South Africa are selected as case studies.
\end{abstract}

Keywords: smart growth, sustainable city, Full Permutation Polygon Synthetic Indicator Method

\section{Introduction}

With the accelerating urbanization process, the city development plan has become particularly important. It is projected that by 2050, 66 percent of the world's population will be urban-this will result in a projected 2.5 billion people being added to the urban population. ${ }^{[1]}$ Unrestricted urban sprawl will bring a series of problems such as shortage of arable land, environmental degradation and so on. So many cities turn to compact development to the effective use of natural resources (including land) and infrastructure (roads and public facilities).

Smart growth is an urban planning and transportation theory that concentrates growth in compact walkable urban centers to avoid sprawl. It also advocates compact, transit-oriented, walkable, bicycle-friendly land use, including neighborhood schools, complete streets, and mixed-use development with a range of housing choices. ${ }^{[2]}$

At present, smart growth in the United States has been actively implemented at different levels and different areas, which produces a good effect. However, the measurement and evaluation criteria of smart growth haven't been decided, and the specific mode of operation needs to be further clarified and refined. Aiming at different regions and urban population, geography and other characteristics, there should be a distinction between the use of smart growth management tools.

\section{Smart Growth Measure Model}

\subsection{Assumptions}

- Yearly statistics can be used validly.

- Indicators will affect each other, but in order to simplify the model, we ignore the interactions between indicators.

- We assume that the land area of each city is not changed during the study.

\subsection{Smart Growth Indicators (SGI)}

In order to measure the success of smart growth of a city, a series of indicators is used, which called Smart Growth Indicator (SGI).

We build a multi-level evaluation indicator system, as is shown in Figure 1. Considering the three E's of sustainability-Economically Prosperous, Socially Equitable, and Environmentally Sustainable, the first level contains three aspects-economy, society and environment. The second level is a further split of the first level. The third level is composed of specific indicators. 


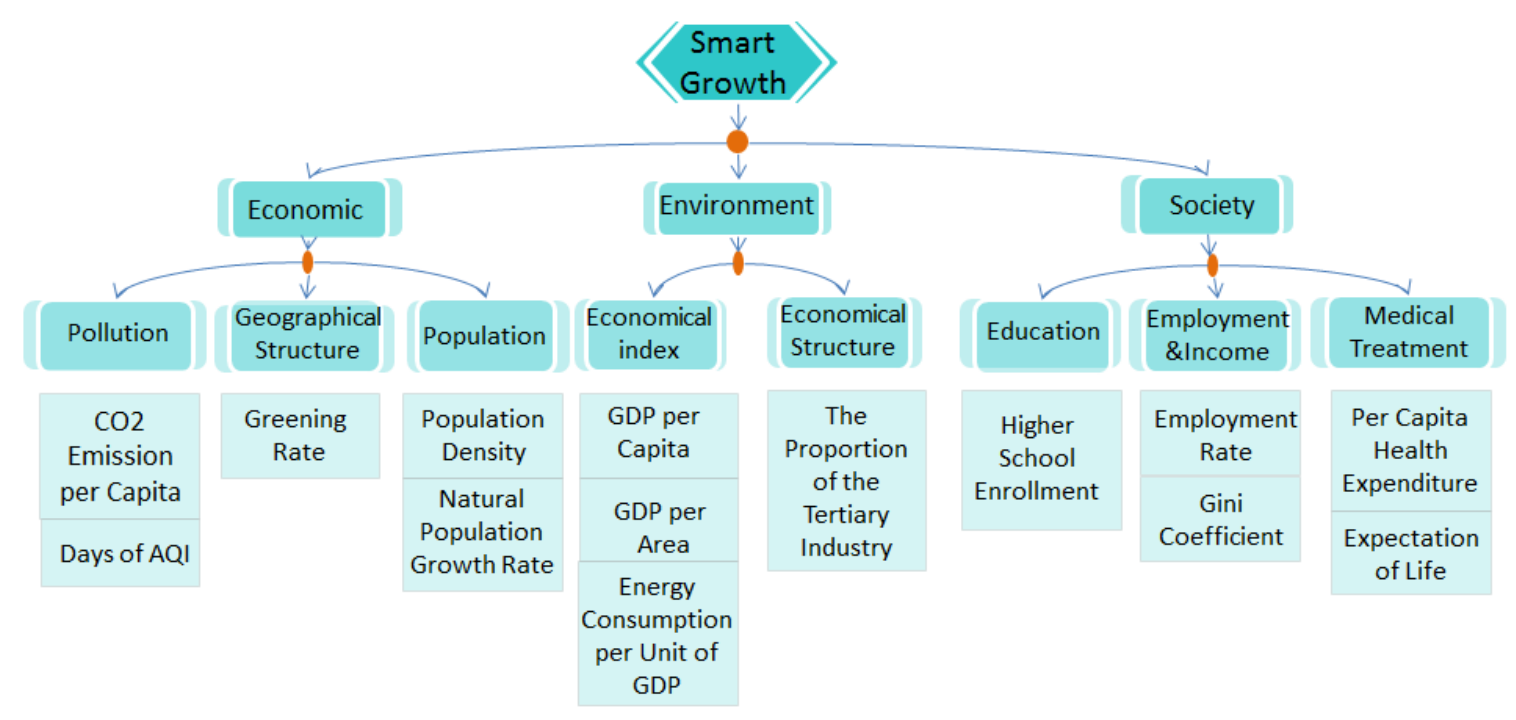

Figure 1. SGI System

The specific explanation of each indicator ${ }^{[3]}$ :

1) $\mathrm{CO} 2$ Emission per Capita (ton per person): This refers to the total carbon dioxide emissions divided by the total population of the city.

2) Days of $\mathrm{AQI}<100$ in a Year (day): Air quality indicator (AQI) reflects the extent of air pollution, when AQI $>100$, we could think air is polluted

3) Greening Rate (\%): This refers to the total area of the city divided by the city and urban peripheral green space area. GDP per Capita (dollar per person): It is an important indicator that measures regional economic situation as well as the level of development.

4) Natural Population Growth Rate (\%): This refers to in a certain period of time (usually one year), the natural population increase number (births minus deaths) divided by the average number.

5) Population Density (person per square kilometer): Population per unit area of land.

6) GDP per Capita (dollar per person): It is an important indicator that measures regional economic situation as well as the level of development.

7) GDP per Area (dollar per square kilometer): This refers to the valve of GDP per square kilometer of land in urban areas.

8) Energy Consumption per Unit of GDP (million tons of standard coal): This refers to the amount of energy consumption per unit of GDP in a given area during a given period of time.

9) The Proportion of the Tertiary Industry (\%): This is expressed as dividing the total value of the three industries (agriculture, industry and service industry) by the annual output value of the tertiary industry (service industry) in a certain area. The higher the proportion of the tertiary industries in the city, the better the industrial structure of the city.

10) Gini Coefficient: This refers to the proportion of the income that is used for the non-average distribution in the income of all the residents. It is an important indicator to analyze the difference of resident income distribution in the world. The smaller the Gini Coefficient, the more equal income distribution.

11) Per Capita Health Expenditure (dollar per person): This refers to the personal spending on health.

12) Expectation of Life (year): This refers to the average life expectancy of the population in the region.

13) Employment Rate (\%): This refers to the total population over 16 years old divided by employed population.

14) Higher School Enrollment (\%): This refers to the ratio of higher education to the number of school-age population. 


\subsection{Full Permutation Polygon Synthetic Indicator Method}

Full Permutation Polygon Synthetic Indicator Method ${ }^{[5]}$ doesn't need to judge the weight coefficient, which greatly reduces the subjective arbitrariness of the evaluation. So we choose to use it to evaluate.

Assume a total of $n$ indicators (normalized values). Taking the upper limit of these indexes as the radius, a central $n$ shape is formed. The lines of each index form an irregular $n$ edge. The vertices of this irregular $n$ edge are the full permutation of the $n$ indicators. The $n$ indicators can form $(n-1) ! / 2$ different irregular $n$ edge. The composite index is defined as the ratio of the mean of all the irregular polygon area to the central polygon area.

Step 1. Standardization of indicators

The standardization of the indicator value is based on hyperbolic standardization function

$$
F(x)=\frac{a}{b x+c}
$$

Located in the interval $[L, U]$ index values mapped to the interval $[-1,1]$. Assume that $L$ is the lower bound of the indicator $x, T$ is the critical valve of the indicator $x, U$ is the up bound of the indicator $X$. Meet the conditions: $F(L)=-1, F(T)=0, F(U)=1$.

For the indicator $i$, the standardized formula is

$$
x_{i}^{*}=\frac{\left(U_{i}-L_{i}\right)\left(x_{i}-T_{i}\right)}{\left(U_{i}+L_{i}-2 T_{i}\right) x_{i}+U_{i} T_{i}+L_{i} T_{i}-2 L_{i} U_{i}}
$$

Where: $L_{i}, T_{i}, U_{i}$ is respectively the minimum value, the critical value and the maximum value of the indicator $x_{i}$

\section{Step 2. Calculation of polygon area}

By using the $n$ indicators, we can make a central $n$ positive edge, the $n$ vertices of $n$ edges are the valves of $S_{i}=1$, the central point are the valves of $S_{i}=-1$.The central point to the vertex of the line for each indicator standardized value of the interval $[-1,1]$, When $S_{i}=0$, the constructed polygon is the critical region of the indicator. The inner region of the critical region indicates that the normalized value of each index is below the critical value, its value is negative. The external area indicates that the normalized value of each index is above the critical value, and the value is positive, which are shown in the Figure 2.

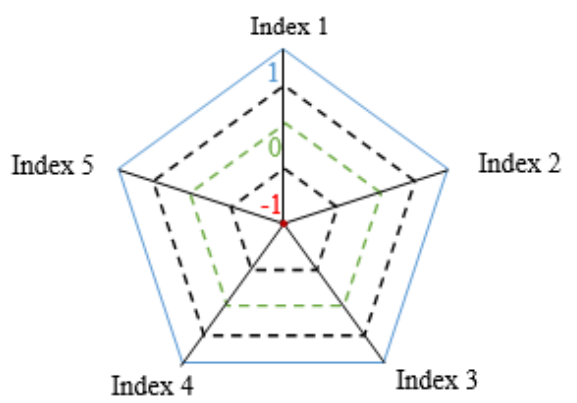

Figure 2. the schematic of Full Permutation Polygon Synthetic Indicator Method

The average area of all the irregular polygons is

$$
S_{1}=\frac{\frac{1}{2} \sin \left(\frac{2 \pi}{n}\right) \sum_{i \neq j}\left(x_{i}^{*}+1\right)\left(x_{j}^{*}+1\right)}{\frac{n-1}{2}}
$$

The area of standard polygon is

$$
S_{2}=\frac{1}{2} \sin \left(\frac{2 \pi}{n}\right) \times 2^{2} \times n
$$


Step 3. Calculation of Comprehensive Indicator (CI) Comprehensive indicator of permutations polygons is

$$
C I=\frac{S_{1}}{S_{2}}=\frac{\sum_{i \neq j}\left(x_{i}^{*}+1\right)\left(x_{j}^{*}+1\right)}{2 n(n-1)}
$$

\section{Case Study}

First of all, we select two cities on two different continents, namely Hartford, Connecticut, US and Bloemfontein, Free State, South Africa. Then, we collected the history data of selected cities ${ }^{[5]}$ to calculate indicators. Using the method of Grey Prediction, we predict prospective indicators of the cities under the current trend of development. And then, we use the Smart Growth Measure Model to measure and discuss how the current growth plan of each city meets the smart growth principles.

With historical indicator data from 2005 to 2015, we figure out the CI value of each city (Table 1).

Table 1. Evaluation Result of Current Plan

\begin{tabular}{ccc}
\hline CI & Hartford & Bloemfontein \\
\hline Degree of Success & 0.9202 & 0.7597 \\
Environment & 0.9667 & 0.9251 \\
Economic & 0.8646 & 0.5649 \\
Society & 0.9192 & 0.7455 \\
\hline
\end{tabular}

As shown in the table, Hartford meets the smart growth principles very well. In three aspects, environment meets the principle best and economic worst. Bloemfontein is far lower than Hartford. The economic aspect is obviously lacking. The difference in two cities' result has great relevance with their current plan.

\section{Conclusions}

There are many factors to consider in the evaluation of smart growth, such as population, growth needs, geographical conditions of specific cities and so on. Therefore, it is very difficult to establish a perfect evaluation index. Our model selects 14 indicators to measure and discuss the current growth plan of each city, which allows us to make substantive conclusions about the success of each city's growth plan. Besides the full permutation polygon graphic index method doesn't need to evaluate weight coefficient subjectively, which greatly reduces the subjective arbitrariness. By using two specific cases to demonstrate our models, it indicates that Hartford's current plans are excellent and Bloemfontein's current plans are fine. This verifies the correctness of our model.

\section{References}

[1] World Urbanization Prospects. United Nations. 2014.

[2] Boeing; et al. (2014). "LEED-ND and Livability Revisited"

[3] Xin Chen. Study on the Development of New Urban Area Based on Smart Growth [D]. Chang'an University, 2014.

[4] Feng Li, Xusheng Liu, Dan Hu, etc. The City Sustainable Development Appraisal Method and Its Application [J]. Acta Ecologica Sinica, 2007, 27 (11): 4793-4802.

[5] http://www.city-data.com/ 